\title{
A methodology for supporting the planning of microgrids based on composable tools: A case in Bhutan
}

\author{
Håkon Duus ${ }^{a}$, Stefano Mandelli ${ }^{b}$, Marta Molinas ${ }^{c}$ and Olav Bjarte Fosso ${ }^{d}$ \\ ${ }^{a}$ Department of Electric Power Engineering \\ Norwegian University of Science and Technology, Trondheim, Norway \\ Email: hakondu@stud.ntnu.no \\ ${ }^{b}$ Politecnico di Milano, Milan, Italy \\ Email: stefano.mandelli@polimi.it \\ ${ }^{c}$ Department of Engineering Cybernetics, \\ Norwegian University of Science and Technology \\ Email: marta.molinas@ntnu.no \\ ${ }^{d}$ Email: olav.fosso@ntnu.no
}

\begin{abstract}
PV-micro-grids are becoming an affordable alternative to provide electricity access to isolated or remote regions due to both a reduction in prices and a strong focus on the free availability of renewable energy sources. When designing these microgrids, the use of optimization methods has been rather limited. Flexible systematic design tools that can adapt to different project sizes, the lack of data, and the different systems constraints, are of limited availability. This paper presents a methodology for a cost-effective design of microgrids based on composable tools using optimization. The optimization is aimed at identifying the optimum size of components for a required performance with the minimum possible cost due to given budget constraints. The developed methodology for optimizing micro-grids is then applied to an off-grid PV microgrid installation in Bhutan.
\end{abstract}

Keywords-Load profile; Off-grid; Photovoltaics; Renewable; Sizing

\section{INTRODUCTION}

With increasing focus on the free availability of renewable energy sources, and the continuing reduction in prices of solar panels [1], PV microgrids are becoming increasingly popular. Moreover, they have many advantages, such as flexibility in scale and location, and low maintenance cost. These are good properties to locally enhance the strength of the main grid with on-grid systems, but also for making off-grid systems in rural areas in order to promote access to electricity.

Traditionally these micro-grids have been designed using a rather ad hoc approach, with limited use of optimization tools that naturally could approach the problem from resource assessment to final electricity use [2], [3]. Optimization-based design taking into account the overall energy profile of the micro-grid, will become an important element of planning tools for micro-grids. Nevertheless, available tools, such as Homer and RETScreen [4], [5], do not provide adequate flexibility for the designers related to the different application contexts. Hence, there is still room for improvement in developing such tools.
A methodology based on composable tools using optimization techniques is presented in this paper and applied to a case-study; a hostel at the College of Science and Technology (CST) in Phuentsholing, Bhutan.

\section{About the Project}

\section{A. Renewable Energy in Bhutan}

In the Tenth Five-Year Plan of Bhutan [6] the Government states that their goal is to provide $100 \%$ of the population with electricity within 2013, including rural areas $(87 \%$ had access to electricity in rural areas in 2012 [7]). Combined with the Alternate Renewable Energy Policy of 2013, which clearly recognizes the need for an increase in renewable energy in Bhutan to "strengthen national energy security" [8], this opens for many opportunities for building new renewable energy in the country. Since much of the country still lacks a proper electricity grid, a good solution for remote villages is to use off-grid PV-solutions with battery-banks [9]. This is easy to install, relatively inexpensive compared to hydropower and requires no additional fuel after installation, as is the case for diesel generators. Today Bhutan gets almost all of its energy from hydropower [10], and is consequently dependent on sufficient water resources to meet a growing energy demand. With melting glaciers and change in rain-patterns, the need for looking at other renewable power resources has been addressed by the Government in Bhutan [10].

\section{B. Why Solar}

In terms of carbon emissions, Bhutan can be considered a net carbon sink. This is due to almost all electricity being produced from hydropower, together with a very keen interest in keeping the country's forests. At the Copenhagen Climate Conference in 2009 (COP15) Bhutan promised to remain carbon neutral [11], [12], which speaks greatly in favour

978-1-4673-7172-8/15/\$31.00 (C)2015 IEEE 


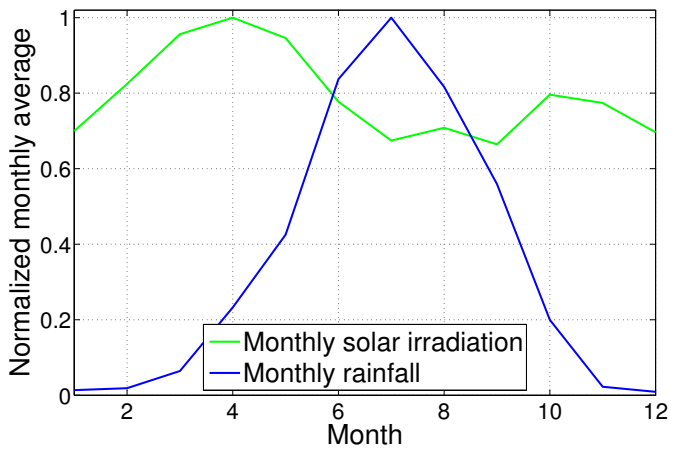

Fig. 1. Monthly solar irradiation and rainfall in Bhutan, normalized so annual maximum is equal to one for better internal comparison.

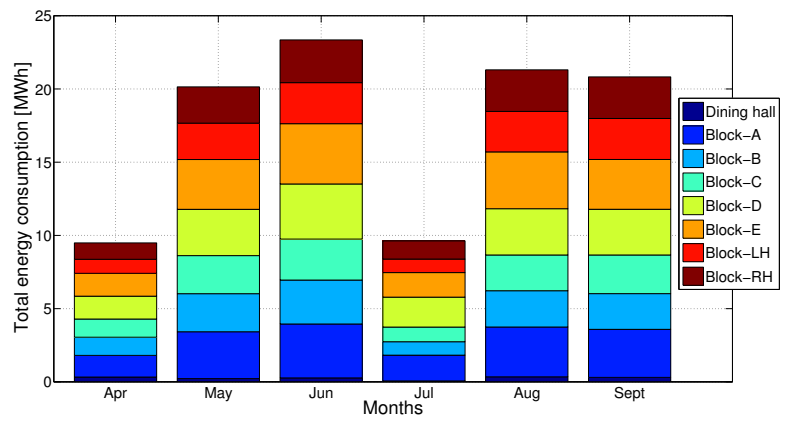

Fig. 2. Monthly energy consumption in the student hostel, divided per block. Only half of April has been measured due to late installation of measurement equipment, and summer vacation is in July, hence the low values for these months.

of using renewable resources instead of diesel-engines for running off-grid installations. Additionally, the solar potential in Bhutan is estimated to about $3000 \mathrm{MW}$ [10], but very little of this potential is exploited.

Furthermore, most of the hydropower-plants in the country are run-of-the-river-plants, which provide no storage capacity, making them exposed to the volatility in water levels over the seasons [13]. Solar irradiation pattern in Bhutan complements very well with this water inflow, thus providing an alternative energy source when water is in scarcity. This is illustrated in Figure 1. The values are normalized to their respective maxima, in order to better illustrate the annual change relative to each other [14], [15].

\section{Educational Purpose}

In order to keep a long-term vision and stable development within renewable energy, it is fundamental to start building knowledge at the universities, both among students and staff. This project is a part of an International Master Programme in Renewable Energy and Hydropower, with the purpose of deploying a prototype microgrid at CST, an engineering-college of The Royal University of Bhutan (RUB). It is developed as a joint project between RUB, and the Norwegian University of Science and Technology (NTNU).

Having a pilot microgrid in the campus will greatly increase the learning outcome for students and staff, as it

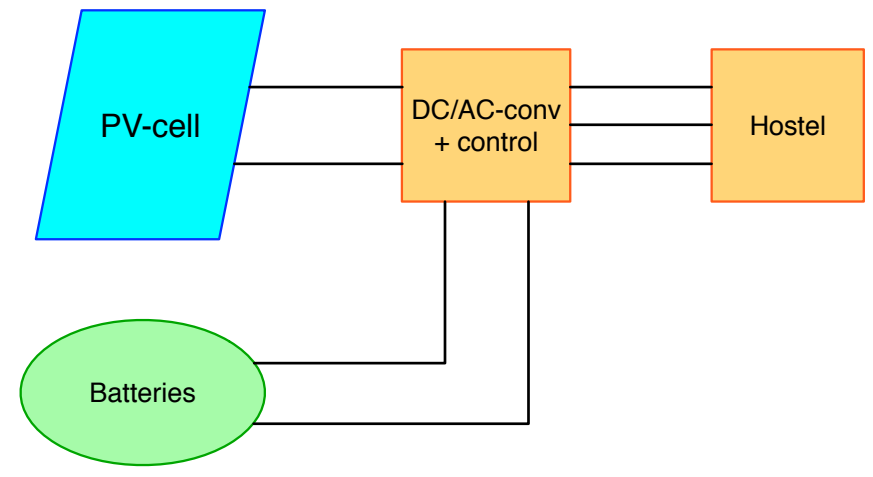

Fig. 3. Simple scetch of system layout. The DC/AC converter functions as control for system voltage and frequency, and batteries are connected to the DC-side of the converter.

opens the possibilities for learning by doing, and this is an important step in building knowledge capacity on renewables in the country. It will aid the students in building a longterm sustainable renewable sector in Bhutan based on multiple resources. After installation the micro-grid will provide the hostel with free energy, which reduces energy expenses for the facility.

\section{Microgrid Design ApProACH}

A methodology based on composable tools using optimization techniques is presented in this paper and applied to a casestudy. A first tool permits to overcome the lack of important electric consumption data, while a second one permits to take a decision in relation to the dimensioning of several microgrid components. The main advantage of the methodology is that a preliminary design decision can be taken having limited access to critical information by performing a systematic study of different design scenarios. The overall methodology has been applied for a case-study considering a student hostel in Bhutan that has decided to change from a grid-connected supply system to a hybrid solution, where part of their energy demand is covered by a PV-microgrid. This installation will consist of a battery-bank, PV-panels, an inverter and controls for the system (Figure 3).

\section{A. The Student Hostel}

The student hostel consists of 7 hostel blocks, Block AE, RK Hostel LH and RK Hostel RH. There is also a dining hall, but this is not included in any further analysis. This is considered to be an acceptable simplification since the dining room only consumes $1.5 \%$ of the total energy consumption (Table II).

Lack of sufficient data to make final decisions has been the main challenge, both related to sizing of the panels and of the accompanying battery pack. To properly size a PV-system to a load, it is desirable to have a full year load-profile with hourly resolution, along with solar data for the area. Global monthly readings on solar irradiation are collected by NASA [15]. In [16] the solar data from NASA are compared with local weather data from Department of Energy, Ministry of Economic Affairs (MoEA). These were found to only have a 
TABLE I. OVERVIEW OF APPLIANCES AND RESPECTIVE ENERGY CONSUMPTION PER DAY IN THE STUDENT HOSTEL, BLOCK-D

\begin{tabular}{|c|c|c|c|c|}
\hline Appliances & $\#$ & $P[W]$ & Use $[h /$ day $]$ & E/day $[k W h]$ \\
\hline Fans & 41 & 50 & 14 & 28,7 \\
\hline Tube Light & 94 & 40 & 5 & 18,8 \\
\hline Incandescent bulb & 66 & 100 & 5 & 33 \\
\hline Water boiler (small) & 12 & 610 & 1 & 7,32 \\
\hline Water boiler (large) & 9 & 670 & 1 & 6,03 \\
\hline Water boiler (instant) & 5 & 1500 & 1 & 7,5 \\
\hline Music sets & 10 & 30 & 2 & 0,6 \\
\hline Laptops & 78 & 55 & 5 & 21,45 \\
\hline SUM & & & & $\mathbf{1 2 3 , 4}$ \\
\hline
\end{tabular}

TABLE II. MONTLY ENERGY CONSUMPTION PER HOSTEL-BLOCK IN $[k W h]$

\begin{tabular}{|c|c|c|c|c|c|c|}
\hline Block & April & May & June & July & Aug & Sept \\
\hline Dining hall & 329 & 222 & 270 & 63 & 344 & 304 \\
\hline Hostel block-A & 1480 & 3200 & 3680 & 1760 & 3400 & 3280 \\
\hline Hostel block-B & 1240 & 2600 & 3000 & 920 & 2480 & 2440 \\
\hline Hostel block-C & 1240 & 2600 & 2800 & 1000 & 2440 & 2640 \\
\hline Hostel block-D & 1560 & 3160 & 3760 & 2040 & 3160 & 3120 \\
\hline Hostel block-E & 1560 & 3400 & 4120 & 1680 & 3880 & 3400 \\
\hline RK Hostel LH & 960 & 2480 & 2800 & 920 & 2760 & 2800 \\
\hline RK Hostel RH & 1120 & 2480 & 2920 & 1240 & 2840 & 2840 \\
\hline \hline Total $[k W h]$ & $\mathbf{9 4 8 9}$ & $\mathbf{2 0 1 4 2}$ & $\mathbf{2 3 3 5 0}$ & $\mathbf{9 6 2 3}$ & $\mathbf{2 1 3 0 4}$ & $\mathbf{2 0 8 2 4}$ \\
\hline
\end{tabular}

deviation of $\pm 10 \%$ and thus the data from NASA was deemed sufficiently accurate for this model.

The solar data used in this paper are collected from the town of Phuentsholing in Bhutan. This monthly data is turned in to a full-year profile with hourly resolution utilizing the already existing integrated algorithm in HOMER. The hourly irradiance profile of the sun is given in $k W / m^{2}$ over the year.

Available data from the hostel is monthly energy consumption for the different blocks, and appliance data for block-D. Appliance-data include number of operating hours per day, power-consumption and type of appliance (Table I). As the metering equipment were installed in April 2014, the value on energy consumption this month is low compared to other months. Summer vacation is in Bhutan is July, resulting in low energy consumption this month also, since the students are not living in the hostel at this time. The measurements were made during the summer months of 2014 , hence there are only data for this period.

\section{B. Identification of the Load Profile}

An equivalent profile for the load with hourly resolution is not available in this case, and needs to be modelled. This is done by reading monthly values of electricity consumption from all the different hostel blocks (Table II), along with data on electrical appliances from block-D (Table I).

To find the number of appliances in the other blocks, the following two assumption were made:

$$
\begin{gathered}
\frac{\text { Energy }}{\text { room }}=\text { const }_{1} \\
\frac{\text { \#appliances }}{\text { room }}=\text { const }_{2}
\end{gathered}
$$

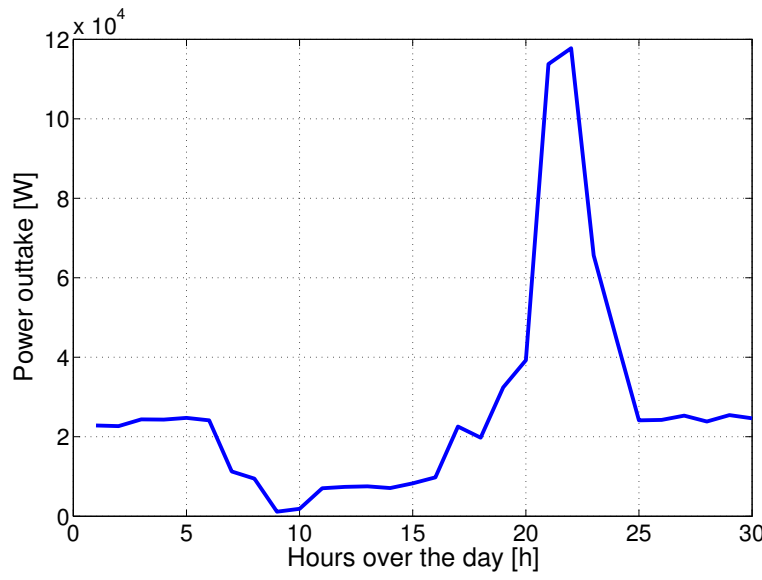

Fig. 4. Synthesized load profile for the student hostel. First day of the year, with stochastic daily variation. Peak-load is in the evening/night due to cooking and the use of cooling fans at these hours.

Combining (1) and (2), gives:

$$
\frac{\text { \#appliances }}{\text { Energy }}=\text { const }_{1} * \text { const }_{2}
$$

Knowing the number of rooms, the monthly energy consumption and number of appliances in block-D, these equations can be solved also for the other blocks, which gives the total number of each appliance in each block.

The monthly energy consumption in each block is known, and with the information from block-D the total number of appliances in the hostel-complex can be estimated.

The final step before it is possible to synthesize a realistic daily profile for the hostel, is to set appropriate operating hours for the appliances. It is important that the total energy used by the appliances coincide with the metered values for the month. This was done for each block in the hostel, with June as dimensioning month.

Feeding all this data on appliances, power consumption per appliance, operating hours and times over the day, into a MATLAB-program, a daily load-profile with hourly resolution can be synthesized. The program has been developed at the Department of Energy at Politecnico di Milano, and creates the load profiles with some stochastic day-to-day variation [17]. Running the model for this daily profile 365 times, a full year profile was obtained, however with no seasonal variation, or change from weekday to weekend (Figure 4).

Utilizing June as dimensioning month, and not adding seasonal variability with lower consumption in other parts of the year might result in a better annual performance than what is depicted in this paper.

\section{Optimization Scheme}

To identify the optimal size of the microgrid, a second simplified MATLAB-model is used [18], taking into account the cost for PV, batteries, their respective lifetime, along with solar irradiation data and the load profile. The last parameter to decide is the accepted Loss of Load Probability (LOLP), 
giving a number on how often it will be acceptable to remain without power. Setting this parameter mainly depends on the end user, what the power is used for, and what is acceptable for the end users. In Norway the annual LOLP for the main grid in 2013 was $0.03 \%$ [19], whereas a microgrd in Visakhapatnam, India is designed for about $8 \%$ annual LOLP [20].

Using the model to analyse the impact of different LOLPs gave a curve showing Net Present Cost (NPC), in euros, of the system with respect to LOLP. Every point on the curve represents an optimal microgrid size, specifying the PV and battery capacity, for the given LOLP (Figure 5). From this curve it is possible to take an informed decision of the optimal system, based on the total budget available and accepted LOLP.

Before testing the model on the load profile based on data from Bhutan, the model was tested for six other profiles. Two dummy-profiles, one profile with constant consumption for all hours, all year, and three profiles based on annual consumption in Norway, for 2009, 2011 and 2013 respectively [21]. The Norwegian consumption data was scaled down and normalized to fit better with the energy used, while keeping the individual variation between the days, and also the seasonal variations. Most of the base-load was also removed, to better represent close-to-zero consumption during night-time.

For proper internal comparison between these six profiles, they were all scaled to have the same annual energy demand, but keeping their individual profile. It can be seen in Figure 5 that all the LOLP-NPC-lines have the same characteristics, even though some of the load-profiles have considered seasonal variations, and some have not.

\section{Scalability}

To see if the investment cost to loss of load probability (LOLP) would increase linearly, double and triple load profiles were made simply by scaling energy-consumption of the original profiles twofold and threefold respectively. The NPCs of these scaled load-profiles were compared to that of multiplying the NPC of the original system by respective multiplier at equivalent LOLP. The findings were that the simplified model scaled linearly with annual consumption.

Running the model with the load profile prepared for the CST-hostel, with the same annual energy as the before mentioned profiles, results in Figure 5.

The resulting LOLP-NPC curve for the Bhutan-profile is shifted far to the right (in black) compared to the others. This is due to a very heavy evening-load (Figure 4), which consequently have less solar resources at these hours. To deliver the same annual amount of energy, the battery-packs must be increased, to compensate for the lack of solar resources in the evening, which in turn increases the investment cost.

The main observation from the results is that the NPC scales linearly to the annual energy demand, given unchanged characteristics of the load profile. This is especially useful in cases like this, when first the load is modelled, and then need to be fit within a budget, as the system easily can be scaled down to accommodate for a lower budget.

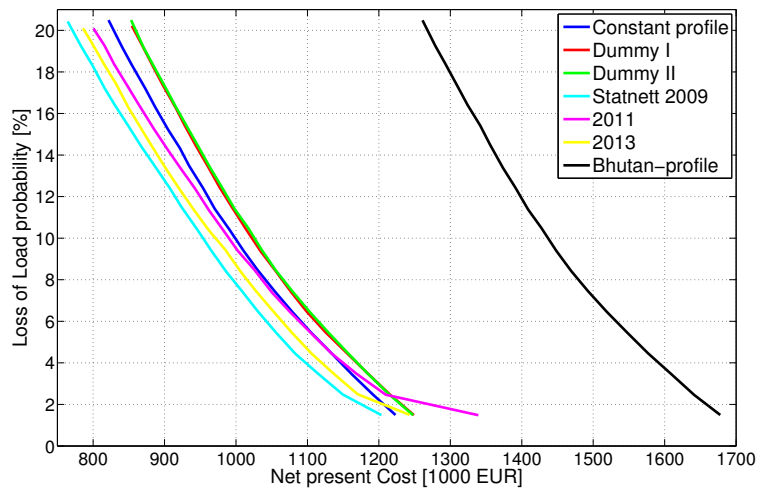

Fig. 5. Loss of load probability to Net present cost, with dummy profiles to the left and synthesized load curve for Bhutan to the right (in black). All curves are based on load profiles with same annual energy, but different load profiles.

\section{Available Funding as a Constraint}

In this paper, a real system is studied, and thus the available funding has to be considered. The budget only represents the net investment cost, and not the total system cost over the lifespan, which is the NPC. The code is therefore modified to estimate the investment cost (IC), and not the NPC. This means removing operation and maintenance cost for the system, and the cost on replacing batteries.

\section{A. Assumptions on Costs}

As the retail price on PV and batteries for this project is not yet decided, it has been estimated that the prices on PV will be about $1000 \mathrm{EUR} / \mathrm{kW}$, the inverter about $500 \mathrm{EUR} / \mathrm{kW}$ [22], and the batteries will be about $140 \mathrm{EUR} / \mathrm{kWh}$.

\section{B. Application to a Real System}

The budget of the real system is 40000 EUR, and will be the upper limit for IC. This limit is indicated in Figure 6.

Using the budget limit as the investment cost limit constrains the type of system it is possible to implement. Having loads with the same profile as shown in Figure 4, and with annual energy in percent of the originally synthesized system (100\% being the original). Investigating the points along the lines in Figure 6 reveals that the relationship between the batteries and PV panels is only linear down to a LOLP of about $8 \%$. This speaks in favour for the decision made in [20] of setting the LOLP to $8 \%$, as further measures to ensure energy security will result in proportionally larger battery-packs, thus reducing the installed capacity of PV. The increased size of batteries is to ensure electricity even in periods with scarce solar resources.

This shows that knowledge about the load, and the acceptable LOLP-limit for the system, will influence the optimal solution of PV and battery, even within a given budget.

From the Figure 6 it is clear that the load possible to satisfy within the budget varies from about $5 \%$ to $7 \%$ of the original load, depending on accepted LOLP. Based on these results, it is clear that the load-profile of the system in question, along 


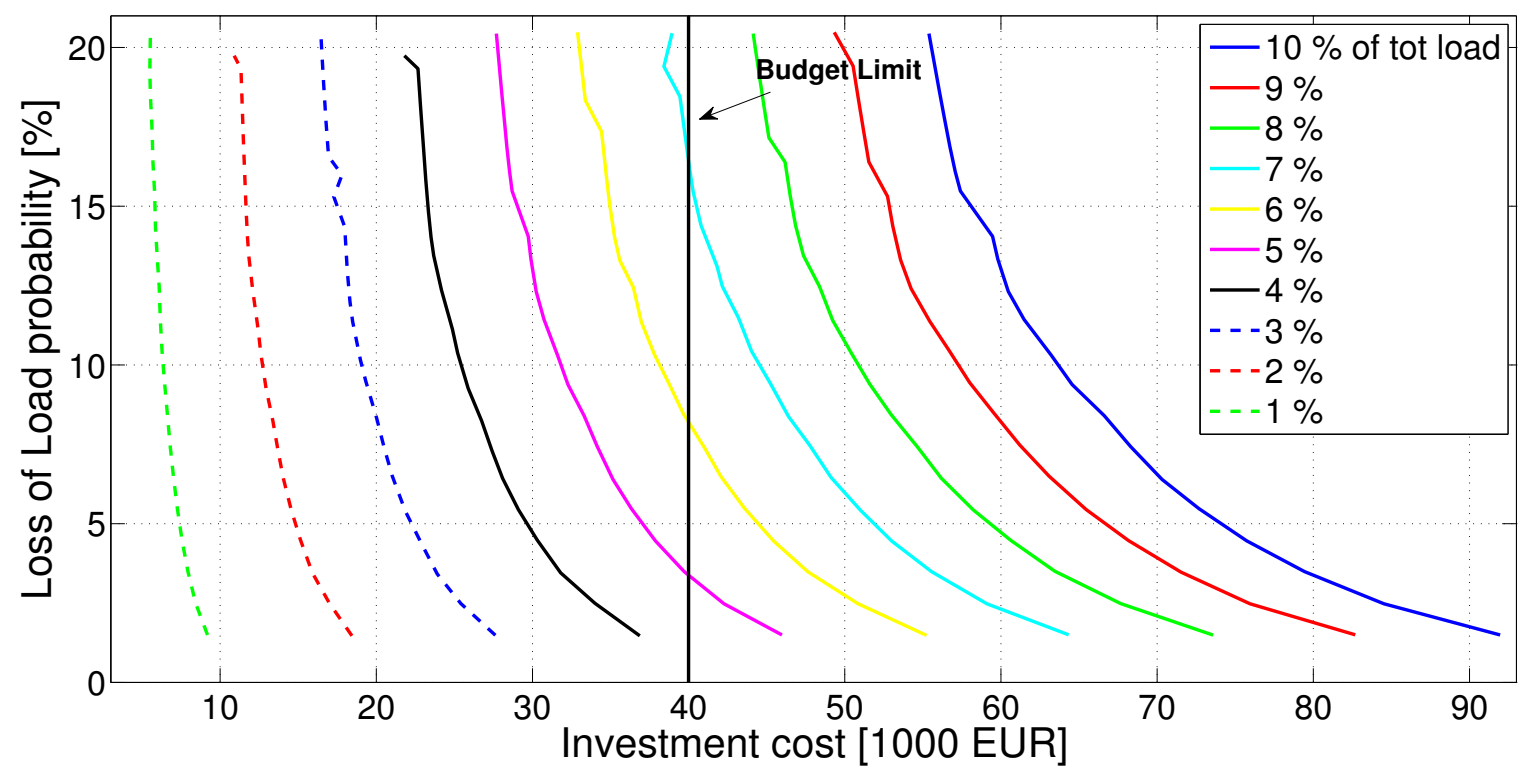

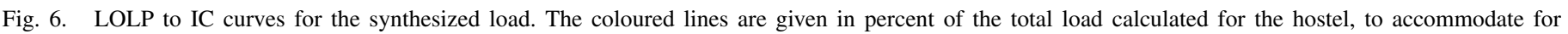
budget constraint

with the accepted LOLP, affects the optimal composition of the system.

\section{CONCLUSION}

Applying MATLAB-models to synthesize annual loads, based on limited data, assist to a large extent in the decision making process, and enables the use of annual simulation models for the given system. In order to cover the needs of the end user and maximize the cost-benefit, optimization methods will become increasingly important due to their capability to systematically compare feasible combinations and search for the best one due to given criteria. Such techniques should be applied early in the process when the potential for saving is the largest.

The use of the composable tools presented in this paper allows for a simpler comparison between several different loadprofiles, and of different sizes, than is presently available. However, these are simplified tools, and for more detailed analysis, other tools and programs must be utilized.

Important parameters, such as LOLP, needs to be defined in order to properly optimize the system. This parameter is also decisive for the applied load, and increasing the load without enhancing the system will result in changed LOLP-values.

As this microgrid will be a research-installation at an already electrified location, a high LOLP from the microgrid is acceptable, as the remaining electricity can be supplied from the main grid. With the presented data and constraints, the size of this system will be of $170 \mathrm{~kW} \mathrm{PV}$ and $800 \mathrm{kWh}$ battery capacity.

Further analysis will include the use of HOMER, which gives access to more detailed component models, and simulates the electrical part to a greater extent. Also, seasonal variation in power consumption must be considered.

\section{REFERENCES}

[1] Clean Technica (2014, Sept), 13 Charts on Solar Panel Cost and Growth Trends,

Available FTP: http://cleantechnica.com/2014/09/04/solar-panel-costtrends-10-charts/

[2] T. Khatib, A. Mohamed, and K. Sopian, A review of photovoltaic systems size optimization techniques, Renew. Sustain. Energy Rev., vol. 22, pp. 454465, 2013.

[3] S. C. Bhattacharyya, Review of alternative methodologies for analysing off-grid electricity supply, Renew. Sustain. Energy Rev., vol. 16, no. 1, pp. 677694, 2012.

[4] HOMER Energy LLC, (2014, Sept.), Homer Energy Available FTP: http://www.homerenergy.com/index.html

[5] RETScreen International, (2014, Sept.), RETScreen software, Available FTP: http://www.retscreen.net/ang/home.php

[6] Gross National Happiness Commission, Royal Government of Bhutan, Tenth five year plan 2008-2013, vol. I, page 114

[7] Gross National Happiness Comission, Royal Government of Bhutan "Saarc development goals, Country report 2012", 2013, page 23

[8] Ministry of Economic Affairs, Royal Government of Bhutan, Alternative Renewable Energy Policy, Thimphu, Apr. 2013.

[9] Asian Development Bank, Bhutan : Energy Sector, Aug. 2010, page 38, par. 128

[10] Bhutan Observer,(2014, Nov.), Looking beyond hydropower, Available FTP: http://bhutanobserver.bt/2637-bo-news-aboutlooking_beyond_hydropower.aspx

[11] Ea Energy Analyses and COWI, Bhutan : A national strategy and action plan for low carbon development, 2012, page 15

[12] National Environment Commission, Royal Government of Bhutan, Second National Communication to the UNFCCC, Nov. 2011, page 5

[13] S. Tshering and B. Tamang, Hydropower - Key to sustainable, socioeconomic development of Bhutan, pp. 17.

[14] Climate Change Knowledge Portal, World Bank (2015, Jan.), average monthly rainfall 1900-2009,

Available FTP: http://sdwebx.worldbank.org/climateportal/index.cfm?page= country_historical_climate $\&$ ThisRegion $=$ Asia $\&$ ThisCCode $=$ BTN

[15] Atmospheric Science Data Center (2014, Nov.) NASA surface meteorology and Solar Energy, 
Available $\quad$ FTP: $\quad$ https://eosweb.larc.nasa.gov/cgibin/sse/homer.cgi?email=htya91@kaist.ac.kr

[16] Y. Dolkar, D. ,Jamtsho, T. Lhendup, T. and C. Dorji, ”System design and performance analysis of a grid tied solar PV power system in Bhutan"

[17] C. Brivio, Off-Main-Grid PV Systems : Appropriate Sizing Methodologies in Developing Countries, Politecnico di Milano, 2013.

[18] W. X. Shen, Optimally sizing of solar array and battery in a standalone photovoltaic system in Malaysia, Renew. Energy, vol. 34, pp. 348352 , 2009.

[19] C. Aabakken, H. S. Fadum, A. AŁnestad, F. Hageengen, and R. A. Nordeng, Avbrotsstatistikk 2013, 2014, page 8

[20] S. Fulton and A. Skumanich, New growth markets for PV: Micro-grids in developing countries-A case study, Photovolt. Spec. Conf. ( ), pp. $33063309,2012$.

[21] Statnett SF, (2014, Sept.) Data fra kraftsystemet, Produksjon og forbruk,

Available FTP: http://www.statnett.no/Drift-og-marked/Data-frakraftsystemet/Produksjon-og-forbruk/

[22] Fraunhofer ISE report, (2014, Sept.) Fraunhofer Institute for Solar Energy Systems

Available $\quad$ FTP: $\quad$ http://www.ise.fraunhofer.de/en/downloadsenglisch/pdf-files-englisch/photovoltaics-report-slides.pdf

Note: This report has been updated in October 2014.

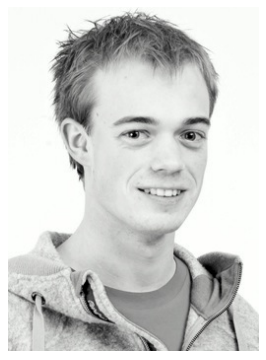

Håkon Duus is currently a graduate student at the Norwegian University of Science and Technology (NTNU) at the Department of Electric Power Engineering, with specialization in Electric Energy Conversion. As a part of his education, he has completed an exchangeyear at École Polytechnique Fédérale de Lausanne in Switzerland.

Stefano Mandelli has a $\mathrm{PhD}$ in En-

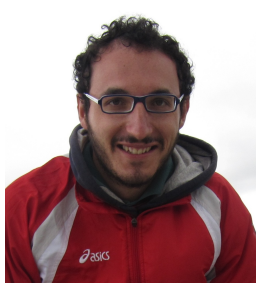
ergy and Nuclear Science and Technology at the Department of Energy, Politecnico di Milano. He is a post-doc researcher at the Dept. of Energy of Politecnico di Milano and he works on small-scale renewable energy systems (off-grid systems, micro-grids) with a special interest for Rural Electrification in Developing Countries. At the moment he is collaborating for the project Energy4Growing for developing and installing a hybrid micro-grid in a rural area of Tanzania.

$\mathrm{He}$ had experience in EU-funded renewable energy related projects in Ethiopia and he worked as national expert for UNIDO-ICS. $\mathrm{He}$ is adjunct professor of "Engineering and Cooperation for Global Development" at the within Environmental and Geomatic Engineering track of the Politecnico di Milano Como Campus.

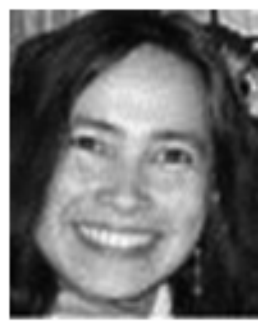

Marta Molinas (M94) received the Diploma degree in electromechanical engineering from the National University of Asuncion, San Lorenzo, Paraguay, in 1992, the M.Sc. degree from the University of the Ryukyus, Nishihara, Japan, in 1997, and the Dr.Eng.degree from the Tokyo Institute of Technology, Meguro, Japan, in 2000.

In 1998, she was a Guest Researcher with the University of Padua, Italy. From 2004 to 2007, she was a Postdoctoral Researcher with the Norwegian University of Science and Technology, Trondheim, Norway, where she has been a Professor since 2008. From 2008 to 2009, she was a JSPS Research Fellow with the Energy Technology Research Institute, National Institute of Advanced Industrial Science and Technology, Tsukuba, Japan. Her research interests include wind/wave energy conversion systems and power electronics and electrical machines in distributed energy systems.

Dr. Molinas is an Active Reviewer for the IEEE TRANSACTIONS ON INDUSTRIAL ELECTRONICS and the IEEE TRANSACTIONS ON POWER ELECTRONICS.

She is an Associate Editor of the IEEE TRANSACTIONS ON Power EleCtronics. She was an Administrative Committee Member of the IEEE Power Electronics Society in 2009-2011.

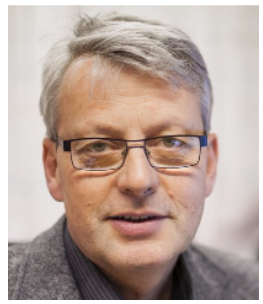

Olav Bjarte Fosso Professor at the Norwegian University of Science and Technology (NTNU) since 2002. Before 2002 he worked at SINTEF Energy on development of methods/principles for utilization of renewable energy in electricity markets and transmission network utilization. He has been chairman of CIGRE SC C5 Electricity Markets and Regulation (2008-2014). He is the NTNU's Board member of NOWITEC (Norwegian Research Centre for Offshore Wind Technology). Currently he is the director of the strategic area energy at NTNU. The research activities involve offshore grid and market integration of intermittent generation. 